\title{
Tipos de empreendedores em penturbia brasileira
}

\author{
Reed Elliot Nelson \\ Universidade Nove de Julho \\ Anderson de Souza Sant'Anna \\ Fundação Dom Cabral
}

Este artigo visa analisar de que forma diferentes atores sociais, em particular os empreendedores locais, se articulam — ou não - na construção de modelo de desenvolvimento econômico regional baseado na noção de penturbia, conforme proposta por Lessinger (1986). Neste artigo, identificou-se a cidade de Tiradentes (MG) como caso exemplar de penturbia brasileira. Em termos metodológicos, a pesquisa que subsidiou seus resultados é de natureza indutiva, orientada pelos princípios da Grounded Theory. De cunho etnográfico, o estudo envolveu análise documental, observação direta e realização de 39 entrevistas semiestruturadas e em profundidade junto a dirigentes de pousadas, restaurantes e ateliês, representantes de fundações e associações de artesãos, membros da igreja e políticos. Para o tratamento dos dados fez-se uso do software N-vivo 8.0. Como resultado foi possível a identificação de duas grandes categorias de empreendedores, emergentes das antinomias locais. Tais categorias, por sua vez, subdividiram-se em subcategorias, as quais refletem, bem como desafiam, tipologias internacionais de artesão, artista, bricoleur e engenheiro. A frequência e a orientação dessas categorias para com modelos alternativos de desenvolvimento local têm importantes implicações para o futuro sociocultural e econômico da cidade.

Palavras-chave: empreendedorismo; empreendedorismo local; ecologia social comunitária; penturbia.

\section{Types of entrepreneurs in Brazilian penturbia}

This paper analyses the role of diverse social actors - particularly entrepreneurs - in the construction of a model of economic development which is descriptive of Lessingers (1986) "Penturbia". We used the town of Tiradentes, Minas Gerais State, as archetypical of the concept and we analyze its developmental trajectory in a grounded theory study. Our research included classic ethnographic methods; analysis of documents, direct observation, and in depth interviews with representatives of restaurants, hotels, studios, foundations, the church, and political figures. We used the N-vivo 8.0 software program to validate our interpretation of interview transcriptions. Our data suggested two general categories of

Artigo recebido em dez. 2010 e aceito em jul. 2011.

RAP - Rio de Janeiro 46(2):453-75, mar./abr. 2012 
entrepreneur which emerged from oppositional themes in respondent discourse. These categories, in turn were expanded into four additional categories - craftsperson, engineer, bricoleur and artist suggested by the international entrepreneurship literature. The frequency and policy orientation of these categories vis-à-vis local development has important implications for the sociocultural and economic future of the community.

Key WORDs: entrepreneurship; local entrepreneurship; social ecology; penturbia.

\section{Introdução}

A crescente frequência e a projeção dos estudos de empreendedorismo decorrem não somente de interesses quanto às riquezas que eles podem gerar para os empreendedores mas, também, pelos benefícios que o empreendedorismo bem-sucedido traz às comunidades (Dana, 2011; Davidson, 1995; De Soto, 2000; Hindle, 2010; Lee et al., 2000). Uma resultante deste reconhecimento são pesquisas destinadas à investigação de relações entre empreendedorismo e regionalidade, conforme difundidas por publicações como a Entrepreneurshipand Regional Development, que se dedica ao estudo de empreendedorismo e desenvolvimento regional, assim como por estudos frequentes sobre o assunto em outras prestigiosas revistas internacionais (Freeman e Audia, 2006; Mezias e Kuperman, 2001; Owen-Smith e Powell, 2004).

As pesquisas nessa linha reconhecem cada vez mais interações importantes entre a natureza das comunidades e dos empreendedores que nelas atuam (Freeman e Audia, 2006; Lee et al., 2000). Entretanto, constata-se, ainda, pouca indagação sobre a forma que tais relações assumirão no futuro. O objetivo do presente trabalho é avaliar, exploratoriamente, uma das relações que o empreendedorismo e as comunidades podem, possivelmente, seguir no futuro, por meio de estudo etnográfico de empreendedores na comunidade turística de Tiradentes (MG). Central em nossa indagação é o conceito de penturbia, desenvolvido por Jack Lessinger, e sua relação junto aos diferentes atores sociais investigados, em específico, os vários tipos de empreendedores.

\section{Penturbia e tipos de empreendedores}

No ano de 1986, Jack Lessinger, então professor de finanças e desenvolvimento urbano da Universidade de Washington, nos Estados Unidos, escreveu um livro que previa uma mudança paradigmática na cultura e economia norte-americana, resultado do deslocamento de populações dos grandes centros urbanos para pequenas cidades rurais. Essa mudança seria acompanhada não somente por uma revolução nos valores imobiliários como por alterações fundamentais nos valores sociais.

A obra seminal de Lessinger (1986) e subsequentes refinamentos (Lessinger, 2008, 2003, 1991, 1987) alegam que tal mudança paradigmática fundamentar-se-ia, entre outros aspectos, na valorização da comunhão do homem com a natureza, com a arte, com a memó- 
ria histórica, com o comunitarismo, com o voluntarismo e com a conservação dos recursos naturais. As comunidades rurais que enfatizassem esses valores seriam as mais prósperas desta nova era.

A mistura de previsões futuristas com ideologias utópicas de Lessenger e de outros autores que têm ousado prever mudanças sistêmicas importantes sofrem de ambiguidades e equívocos, como se vê nas obras de Toffler (1980), Reich (1991), Riffkin (1995) e mesmo Karl Marx (Hicks, 2004) e muitas previsões de Lessinger ainda se encontram longe de serem concretizadas. Não obstante, seriam poucos os que temeriam dizer que, diante da justaposição de tecnologia, internacionalização e depredação ambiental, o mundo e suas comunidades não estariam na mira de mudanças radicais. Ademais, previsões de Lessinger nas últimas duas décadas têm gozado de considerável poder de predição.

Em sua obra Regions of opportunity, de 1986, Lessinger utilizou regressões múltiplas para atribuir notas às probabilidades de aumento dos valores de imóveis do conjunto das comarcas dos Estados Unidos. Se naquele ano um investidor tivesse investido em imóveis nas regiões de crescimento previstas por Lessinger, teria, hoje, realizado lucros na ordem de várias centenas de pontos percentuais. Mais importante para nossas finalidades, no entanto, é o fato de que algumas comunidades rurais norte-americanas e brasileiras, dotadas de expressiva beleza natural, conservação histórica ou rico patrimônio cultural, experimentam intensa renovação nos moldes da penturbia descrita por Lessinger.

Esse autor não procura prever a natureza interna das comunidades descritas como penturbias, nem dos processos que acompanhariam sua suposta evolução. Da mesma forma, outros modelos alternativos de desenvolvimento comunitário sustentável como o discursivecommunity, discutido por Meppem (2000), ou as economias sustentáveis locais, preconizadas pelo movimento Bioneer (Ausbel, 1997), não têm oferecido análises detalhadas sobre a evolução, transformação e funcionamento de tais comunidades. Por isso, pouco ainda se sabe sobre as dinâmicas dessas comunidades renovadas, quais os principais grupos sociais que as determinaram, como seria a interação entre seus atores e outras questões afins.

Visando ampliar tal debate, o presente artigo relata resultados de pesquisa desenvolvida com o objetivo de investigar de que forma diferentes atores sociais se articulam — ou não - em processos dessa natureza, com destaque para a análise de empreendedores envolvidos em penturbia brasileira e suas interações com a comunidade em geral.

Se Lessinger e outros autores de visões similares tiverem razão e se algum processo análogo à noção de penturbia ocorrer no Brasil, um conhecimento de sua dinâmica social e, especialmente, dos atores sociais envolvidos pode ser importante por motivos práticos e teóricos. E, mesmo que a penturbia não seja uma tendência inexorável, não há dúvidas quanto à importância econômica, social e cultural de localidades que mobilizam recursos culturais, arquitetônicos e naturais como base de novos modelos de desenvolvimento econômico e social, como parece ser o caso de algumas cidades históricas brasileiras e mesmo certos bairros nos grandes centros urbanos.

Grande parte dos ativos imobiliários e financeiros de tais comunidades encontra-se nas mãos de empreendedores capitalistas, e a formulação e a execução de políticas de sustentabi- 
lidade e inclusão social dependerão, em boa parte, das articulações com tais forças produtivas. Em decorrência, pesquisas sobre os tipos de empreendedores dessas regiões e suas inter-relações com demais atores sociais apresentam considerável potencial de estudo e intervenções. Finalmente, pesquisas deste tipo poderiam servir de subsídios para a análise do fenômeno do empreendedorismo local e suas variações no Brasil.

\section{Metodologia e desenvolvimento da pesquisa}

A carência de pesquisas deste tipo, no Brasil, limita o uso de metodologias e perspectivas mais "clássicas", tais como surveys, hipóteses a priori ou técnicas de inferência estatística, assim como o uso prévio de modelos teóricos disponíveis na literatura internacional que não sofreram ainda avaliação crítica para sua adoção no contexto nacional. $\mathrm{O}$ uso de tais métodos e perspectivas traria o risco de impor, indevidamente, lógicas ou categorias cognitivas de um campo ou contexto social a outro (Dey, 2007; Padgett, 2004; Denzin e Lincoln, 2000; Lincoln e Guba, 1985), ocultando observações que poderiam escapar aos quadros teóricos já consolidados. Em decorrência, optou-se, para fins desta pesquisa, por um estudo de campo do tipo Grounded Theory, de cunho mais etnográfico (Glaser, 1992, 1978; Glaser e Strauss, 1967) incluindo, quando possível, fontes históricas e documentais sobre a cidade e região em análise.

Não obstante a adoção de abordagem de tipo Grounded Theory, recorreu-se, ao longo da pesquisa, a considerações quanto a conceitos da literatura em ciências sociais, incluindo obras de autores como Lévi-Strauss (1966) e Bourdieu (2003, 2008), que pudessem orientar e refinar nossas indagações e achados. Revisão de literatura sobre tipologias internacionais de empreendedor também fez parte dos esforços dos pesquisadores, durante e, mormente, após o estudo de campo (Stinchfieldet al., 2010; Zahra et al., 2009; Baker e Nelson, 2005; Cooper et al., 1997; Filley e Aldag, 1978; Smith, 1967).

O estudo iniciou-se com a análise de documentos sobre a comunidade que pudessem descrever seu contexto econômico e social, ao longo de sua história. Nessa etapa, procurou-se descrever seus estágios de desenvolvimento econômico e social. Durante o período 2009-11, foram realizadas nove visitas in loco a Tiradentes. Além de observações gerais sobre a configuração dos empreendimentos, das atividades culturais da cidade, do uso do espaço físico, da distribuição e fluxo de turistas e dos cidadãos locais, foram realizadas 39 entrevistas em profundidade junto a dirigentes de pousadas, restaurantes, ateliês, fundações, associações de artesãos, membros da igreja e representantes da classe política da cidade.

\section{A lógica da pesquisa}

Para fins deste estudo, primeiramente, reuniu-se o máximo de dados históricos formais sobre a cidade e suas redondezas. Na sequência, procedeu-se a entrevistas semiestruturadas e em profundidade com informantes presentes na cidade durante diferentes períodos de seu 
desenvolvimento e/ou que tinham tido algum envolvimento ou contato pessoal com pessoas identificadas como tendo estado, pessoalmente, envolvidas no processo de sua transição para o estágio atual de desenvolvimento econômico. Para tal, fez-se uso de uma amostragem intencional, visando entrevistar diferentes atores sociais protagonistas desse processo, em especial, proprietários e responsáveis por ampla gama de empreendimentos na cidade.

À medida que a pesquisa se desenvolvia, a literatura relacionada a empreendedorismo, desenvolvimento comunitário e, também, a outros relevantes trabalhos sociológicos foi revisada, permitindo, desse modo, reorientações quanto ao escopo das entrevistas e reinterpretações dos achados obtidos, ensejando a produção de textos preliminares (Sant'Anna, Nelson e Oliveira, 2011; Sant'Anna, Nelson e Campos, 2011).

As entrevistas, que ao todo registraram mais de 60 horas, foram gravadas e, posteriormente, transcritas, propiciando mais de 250 laudas de digitação. O roteiro de entrevistas foi semiestruturado, incluindo questões sobre a trajetória pessoal dos respondentes, suas visões acerca do processo de requalificação de funções econômicas da cidade e dos principais agentes envolvidos nessa dinâmica.

\section{Tratamento dos dados}

Para fins de tratamento dos dados obtidos utilizaram-se, inicialmente, informações do conjunto das fontes consultadas com propósito de reconstituir uma história detalhada da cidade e de sua trajetória econômica e social desde o século XVIII. Procurou-se identificar e caracterizar as fases da evolução da comunidade e os principais atores e forças sociais, econômicas e políticas em jogo durante cada uma das mesmas. Buscou-se, também, identificar, em relação a cada fase, o papel dos principais atores sociais envolvidos e sua exposição pessoal aos eventos que marcaram o processo de desenvolvimento da localidade.

Em seguida, buscou-se identificar as principais categorias cognitivas emergentes das entrevistas procedidas. Além de cuidadosa leitura das transcrições dos relatos obtidos, efetuada pelos autores, empregou-se análise por meio do software de tratamento estatístico $N$-vivo 8.0, a fim de identificar temas e subtemas, a partir dos depoimentos resultantes das entrevistas (Flick, 2009).

Como resultados, foram geradas categorias mutuamente exclusivas e exaustivas (Denzin e Lincoln, 2000; Miles e Huberman, 1994). A partir de tais códigos, foi possível, também, identificar categorias secundárias (Bowen, 2006; Dey, 2007; Gioia e Thomas, 1996). A análise mecânica pouco variou da leitura subjetiva das transcrições. Ambas identificaram diversos temas, categorias e pares antitéticos usados pelos membros da comunidade para descrever a comunidade e seus membros.

A caracterização da história da cidade, juntamente com a análise cognitiva das categorias decorrentes das entrevistas, sugere que diferentes empreendedores ocupam diversas posições no tecido social de Tiradentes. Diferentes maneiras de categorizar os empreendedores 
foram experimentadas, tendo por base informações internas da comunidade, constantes nos dados de campo obtidos.

Isto posto, constatando que se havia exaurido as mais óbvias maneiras de caracterizar os empreendedores da cidade, por meio das categorias implícitas nos dados empíricos levantados, passou-se à literatura sobre empreendedorismo e ecologia comunitária, com vistas a enriquecer a compreensão conceitual acerca da cidade e avaliar a teoria existente, comparativamente às categorias locais propostas, indutivamente. Pesquisou-se, também, a literatura sobre desenvolvimento regional a fim de melhor compreender as interfaces entre comunidade e empreendedorismo, bem como para se confrontar os dados de campo e as categorias obtidas vis-à-vis a literatura. Por último, buscou-se analisar as implicações deste estudo quanto ao preenchimento de lacunas presentes na literatura existente.

\section{Análise dos dados}

\section{A evolução histórica de Tiradentes}

Como nossa pergunta de pesquisa enfatiza a dinâmica comunitária e na medida em que Tiradentes apresenta uma trajetória histórica e econômica única, poderá ser útil fornecer uma breve descrição da comunidade antes de se passar a aspectos mais teóricos.

No início do século XVIII, uma grande quantidade de ouro foi descoberta nas acidentadas e isoladas montanhas do Brasil central. A resultante corrida ao ouro levou mais de 600 mil pessoas - muitas delas escravos oriundos da África - àquela região em um espaço de tempo relativamente curto. Como resultado, um grande número de cidades e vilarejos emergiu ao longo dos depósitos de ouro, estendendo-se por um território de mais de 500 quilômetros de onde as lavras de ouro haviam sido encontradas. Algumas destas cidades, como Ouro Preto, cresceram e chegaram a rivalizar com grandes cidades europeias daquela época, tanto em população, se não também em riqueza. Um crescente número de construções tomou conta da região, incluindo palacetes, igrejas, prédios comerciais e do governo, nos estilos barroco e rococó.

O isolamento da região e a dificuldade de transporte e comunicação levaram ao desenvolvimento de um estilo local bem distinto, que ainda é valioso tanto nacional quanto internacionalmente. Isso foi verdade não só na arquitetura, mas também na arte, na música e na culinária.

Como a distribuição dos veios de ouro e o volume dos depósitos não eram constantes, as comunidades que surgiam eram bem dispersas e de tamanhos distintos. Tiradentes era de tamanho modesto - sua população era de menos de 20 mil pessoas em seu auge e se localizava a cerca de sete quilômetros de outra cidade de mineração, maior, chamada São João del-Rei. Já no início do século XIX seus principais depósitos de ouro haviam, no entanto, se exaurido em definitivo, e a economia da região entrou em colapso. O que sobrou 
da população partiu para a agricultura de subsistência, que se misturava com a de criação de um pequeno volume de animais domésticos, e poucos excedentes de produção agrícola, para comercialização.

A cidade vizinha a Tiradentes, São João del-Rei, também diminuiu de tamanho, mas manteve alguma população não só devido a seu tamanho, mas também à sua localização em importante rota de comércio. Em contraste, a cidade de Tiradentes foi praticamente abandonada, exceto por algumas poucas famílias que se mantiveram na terra e por alguns artesãos que continuaram a trabalhar nos negócios de metal que haviam florescido quando o ouro era abundante. Um dos impactos deste abandono foi a quase completa preservação do conjunto arquitetônico e natural da cidade (Frota, 2005).

\section{A redescoberta da cidade}

Após cerca de um século de abandono, durante a primeira metade do século XX, Tiradentes foi, de certa forma, redescoberta por membros da elite cultural brasileira. Durante esse período registra-se forte movimento nativista que buscava redefinir e celebrar a identidade nacional brasileira. Nesse esforço, o movimento voltou-se para o passado colonial do país (Frota, 2005). Como o isolamento das cidades históricas da época da mineração favoreceu a formação e a preservação de uma identidade cultural única, tais cidades atraíram o interesse da elite intelectual como fonte e símbolo da autêntica cultura brasileira. O tamanho menor e o rápido abandono de Tiradentes, em conjunto com a relativa facilidade de acesso, por meio da cidade próxima, São João del-Rei, favoreceram sua emergência como local para o turismo de elite. Tal renascença recebeu ainda maior impulso quando Maria do Carmo Nabuco, uma rica senhora oriunda de uma dinastia regional, se interessou pela arquitetura da cidade e estabeleceu uma fundação para catalogar e preservar os prédios, os marcos históricos e os artefatos religiosos locais (Frota, 2005).

O tamanho reduzido, a comparativa facilidade de acesso e a preservação da cidade fizeram dela uma localização ideal para a produção de filmes e minisséries de televisão. A cidade passa, por exemplo, a ser frequentemente utilizada como local de filmagem pela principal rede de televisão do Brasil. A produção de filmes e especiais não só tornou a cidade conhecida, mas também envolveu a presença de atores, cineastas e produtores culturais brasileiros, o que reforçou sua exposição à elite e estimulou a demanda por acomodações e restaurantes de alta classe.

Como cidade pequena e acessível, mas não acessível em demasia, e como os visitantes costumeiros pertenciam às elites nacionais, os negócios da cidade tendiam a ser pequenos e de elevado nível de serviços. Tal tendência foi enfatizada pelos decretos governamentais que proibiam a demolição ou alteração substancial dos prédios históricos da cidade.

Até os anos 1990 a cidade não possuía grandes hotéis, restaurantes, centros de convenção ou shoppings centers. As acomodações e restaurantes se concentravam em pequenas pousadas, comumente localizadas em prédios históricos. Atualmente, mais de 200 desses em- 
preendimentos estão espalhados pela cidade. A exposição da cidade em produções de mídia a tornou, no entanto, ao longo do tempo, um destino popular, resultando em tráfego regular de excursões de turismo, aumentando o número de visitantes, mas reduzindo o valor per capita das compras, assim como estimulando o surgimento do comércio de quinquilharias, suvenires e toda sorte de artigos baratos. A cidade, também, começou a patrocinar diferentes tipos de festividades, como o carnaval de rua aos moldes das "axéfolias", atraindo grande público, dos mais variados segmentos de renda.

À medida que a economia brasileira amadureceu e se diversificou, Tiradentes começou a atrair uma leva de profissionais e empreendedores de elevado grau de educação formal, oriundos das classes médias das metrópoles urbanas, que fugiam de empregos nas grandes corporações e acabaram por fundar pousadas, bares, lojas e/ou restaurantes. Esses migrantes, embora mais cosmopolitas e sofisticados, possuíam, não raro, capital econômico modesto. Eles se juntavam, pelas semelhanças quanto a seus capitais simbólicos e econômicos, aos migrantes de épocas anteriores, mais elitizados, assim como a artistas que haviam se interessado pela cidade nas décadas anteriores. Ao mesmo tempo, alguns nativos da região começavam a fundar negócios, muitas vezes usufruindo de terras herdadas e influência de laços familiares e políticos.

O início do século XXI encontrou a cidade próspera, com nível de quase pleno emprego e crescimento robusto, mas, coletivamente, insegura sobre como se manter sustentável e prosperar sem dilapidar os bens naturais e culturais que permitiram seu atual ciclo de desenvolvimento.

Adicionalmente, cabe salientar que, assim como em grande parte das pequenas cidades brasileiras interioranas, sua administração encontra-se nas mãos de famílias locais rivais, que se alternam no poder ao longo de gerações, competindo pela lealdade dos eleitores, não raro, por meio de ações clientelistas e de natureza assistencialista (Faoro, 1979). Tipicamente, um representante de uma família ocupa a prefeitura por um ou dois mandatos, seguido por representante da outra família.

\section{Temas antitéticos}

A trajetória histórica da cidade favoreceu a identificação de diferentes grupos e questões comunitárias que mais tarde puderam ser expressas por meio de pares de conceitos antitéticos amplamente mencionados nas entrevistas. Apesar da atual posição econômica favorável e do pequeno tamanho da comunidade, nossas entrevistas indicaram que a cidade vivencia processo inconcluso de transformação econômica e social, marcado por antíteses e contradições. Quatro temas principais identificados ao longo dos relatos expressam tais tensões: 1. diferenças entre áreas geográficas; 2 . distinção entre nativos e não nativos; 3 . diferenças na filosofia e modelos de negócios dos empreendedores; 4. diferenças nas relações entre os empreendedores e demais segmentos da comunidade. 


\section{Centro vs. periferia}

Especialmente como resultado do notável aumento do tráfego de turistas ocorrido durante os anos 1990, a área histórica do centro da cidade tornou-se bem distinta do resto da cidade. O centro da cidade passa a se dedicar, primariamente, à atividade comercial, apesar dos desejos de algumas pessoas de que a área abrigasse proporção maior de espaços e atividades culturais e de residências. Os proprietários dos empreendimentos, por outro lado, desejam locais no centro da cidade dada a maior parte do tráfego de turistas acontecer nesse espaço. Questões relacionadas ao tráfego de veículos e animais, a localização e as rotas usadas pelo transporte público, a extensão e o aborrecimento causado por obras públicas assumem uma dimensão comparativamente maior quando envolvem a área histórica do centro da cidade. Embora se fale em assegurar a qualidade de vida dos residentes locais, a maioria concordaria que os investimentos na área histórica estariam focados em torná-la "mais amigável aos turistas e não aos residentes". Os costumes, hábitos e o movimento diário dos residentes locais parecem constituir preocupação secundária.

Qualquer espaço que não pertença à área central pertence à categoria de "periferia", que dentro desse quadro pode ser traduzida como "bairros" ou áreas "circunvizinhas" ao centro. Antes do renascimento da cidade como destino turístico, tais áreas contavam com poucos habitantes e eram constituídas por pequenas e rústicas casas e modestas chácaras. Com o redesenvolvimento da cidade, as mesmas se transformaram, sendo ocupadas de três formas contrastantes.

Primeiramente, devido à elevação dos preços dos terrenos de valor histórico na área central, seus antigos habitantes acabaram por vender ou alugar suas propriedades, construindo, nos bairros, residências maiores e mais confortáveis. Outro fator é que, como a periferia não está sujeita às mesmas restrições que o centro histórico na questão do estilo das construções permitidas, empreendimentos maiores em escala - hotéis e grandes lojas, centros de convenção e similares — passam a se localizar também na periferia. Por último, o boom turístico traz para a cidade novos conceitos como o de "condomínios fechados", atraindo residências mais suntuosas, de maior conforto e status.

\section{Nativos vs. não nativos}

Outra dessas antinomias marcantes foi a utilizada para distinguir os "locais" dos "forasteiros". Muito do crescimento populacional da cidade explica-se sob a forma de migrantes atraídos pela atmosfera cultural e localização geográfica de Tiradentes. Os empreendedores nascidos em Tiradentes tendem, no entanto, a empregar estratégias e táticas diferentes em seus negócios comparativamente àqueles que vêm de fora, mas a distinção vai além do modelo e do estilo de negócios, incluindo visão de mundo, capital humano e outros aspectos. Não chega a ser surpreendente que a distinção entre nativos e recém-chegados também tenha sido o foco de certa falta de confiança e tensão, particularmente por parte dos nativos. 
O par antitético usado na cidade para identificar nativos e não nativos é "ETs" e "Minhocas". O simbolismo contido aqui é fácil de ser descrito. O "ET", extraterrestre ou extra-tiradentino implica algo exótico e estranho que talvez conte com conhecimento e capacidade "superiores", mas com uma compreensão limitada do sistema e da dinâmica locais. Por outro lado, os "Minhocas" vêm da terra, e se são mais limitados em seus horizontes são, porém, mais "pés no chão". Tais atribuições expressam bem as percepções e frustrações dos nativos em relação àqueles que vêm de fora, cuja educação formal, experiência cosmopolita e contatos externos fazem com que consigam, aparentemente, com mais facilidade, desenvolver negócios que atraiam uma clientela com o mesmo perfil esotérico e que paga valores "astronômicos" para dormir em prédios antigos e saborear as especialidades da culinária local.

As diferenças culturais entre os "de fora" e os "nativos" geram tensões não só entre os proprietários dos empreendimentos, mas também no campo da política e em relação aos proprietários e seus profissionais, como veremos mais adiante. Apesar de tais tensões, os "ETs" que permanecem em Tiradentes — há um grupo significativo de pessoas que se mudaram para a cidade, mas que a deixaram após alguns anos — parecem se identificar fortemente com a comunidade. Eles não apenas percebem Tiradentes como seu "lar", mas tendem a se considerar como importantes agentes de mudanças, com a missão de melhorar a comunidade social, econômica e politicamente. "Nativo" e "não nativos", e "centro" versus "periferia" parecem constituir as mais importantes e genéricas dinâmicas antitéticas na cidade, mas não são as únicas.

Os três últimos pares opostos que descobrimos em nossas análises covariam e se inter-relacionam com os dois primeiros ("centro-periferia" e "nativos-não nativos"), mas se apresentam mais associados aos modelos de negócios de diferentes empreendedores que no âmbito da comunidade em geral. Há uma importante distinção entre empreendedores que consideram seus negócios como reflexos de sua própria identidade pessoal e missão (projeto de vida) e aqueles para quem seus negócios são vistos em termos mais "utilitários".

A primeira categoria parece mais motivada pela oportunidade de usufruir de um estilo de vida de cidade pequena. Eles não enfatizam o crescimento ou os lucros. Seus negócios são vistos como extensões de suas vidas e parte do papel que desempenham em uma comunidade personalizada, "face a face".

A outra categoria considera seus empreendimentos como respostas a oportunidades percebidas, como a existência de um mercado de consumo não apropriadamente atendido, em decorrência do florescimento econômico durante os anos 1990, quando o tráfego de turistas até a cidade cresceu consideravelmente. Essa segunda categoria frequentemente utiliza a linguagem financeira e de investimentos, enfatizando termos como "crescimento" e "retorno".

Os termos locais usados para descrever tal antinomia foram "bijuteria" versus "joia", sendo o termo "bijuteria" expressão de algo que é uma cópia em relação ao original, a coisa verdadeira, isto é, a "joia”. Mais uma vez, aqui o simbolismo contido nos termos descreve como os informantes percebem as categorias. Uma "joia” é algo valioso e raro, que tem não só valor estético, mas também de status, de prestígio. As "bijuterias" também possuem uma 
proposta estética, mas não são nem caras, nem raras. Em vez disso, são cópias do original ou itens que podem ser atraentes, mas que não são valiosos, nem únicos.

Os empreendimentos “joia” buscam preservar e expressar a cultura única da região em seus produtos e serviços e também imprimem uma orientação de longo prazo a seus empreendimentos. As "bijuterias", por sua vez, são, frequentemente, empreendimentos bem geridos, podem oferecer uma excelente qualidade de serviços, mas não fazem nenhum esforço específico para preservar a identidade e o legado da cidade. Elas estão orientadas para o crescimento, para o volume e para o marketing, engajam-se em "promoções agressivas" e em atividades de gestão que visam unicamente elevar o tráfego de turistas — de dinheiro — para a localidade. Tal distinção sobre a missão e a ética como um todo se estende aos estilos de liderança e aos estilos pessoais encontrados nos empreendimentos.

Descobrimos, ainda, que os empreendimentos "joia” enfatizam, em um grau mais alto, as relações pessoais e o desenvolvimento individual de seus profissionais, enquanto os "bijuteria” enfatizam a eficiência na execução das tarefas. Os empreendimentos “joia” tentam desenvolver seus profissionais muito além do que é exigido por seu ambiente de trabalho imediato. Os proprietários desse grupo matriculam seus profissionais em programas de alfabetização, certificam-se de que frequentam a escola e até mesmo ajudam a pagar seus cursos superiores. Seus empreendimentos apresentam rotatividade menor e os gerentes, frequentemente promovidos a partir dos quadros funcionais existentes, são experientes e leais, permanecendo por longo tempo na "casa". Não é comum encontrar padrões e políticas formalizadas.

Já os proprietários dos empreendimentos "bijuteria" favorecem um ambiente de trabalho menos pessoal e enfatizam aspectos como prazos, padrões explícitos de desempenho, sistemas de avaliação e recompensa baseados em normas formalizadas, assim como na hierarquia para monitorar o comportamento de suas equipes. Nessa questão, eles vão ao encontro da tradição de relações personalistas e de longo prazo, assim como da reciprocidade, típicas de Tiradentes, em particular, e de pequenas comunidades, no Brasil, em geral.

Os empreendimentos "joia" e "bijuteria" associam-se, de maneira próxima, aos dois últimos pares antitéticos que detectamos, preservação versus exploração e coletivismo versus individualismo.

Alguns proprietários, não importando se nascidos em Tiradentes ou não, apresentavam-se preocupados com o crescimento desordenado da cidade e com as tendências de o desenvolvimento dos setores varejista e de restaurantes se sobrepor ao apelo artístico e cultural da comunidade. Eles reforçam a necessidade de se conservar os capitais histórico e cultural locais. Eles, comumente, tecem uma distinção entre "crescimento rápido" e "prosperidade verdadeira" e expressam desejo de que Tiradentes prospere de forma sustentável. São mais sensíveis e mais ativos em relação aos problemas e às deficiências da comunidade nas questões de suprimento e qualidade da água, tratamento de esgoto e gestão do desperdício. Eles não apenas se manifestam sobre tais assuntos, mas também agem para desenvolver a comunidade de uma maneira mais sustentável. No extremo oposto encontravam-se os empreendedores mais individualistas em suas atividades e mais orientados à maximização do desempenho financeiro individual, em oposição à prosperidade coletiva. Seus modelos e táticas de negócios 
aparentam menor preocupação com impactos negativos do crescimento sobre o ambiente histórico da cidade, sua cultura ou com o cotidiano de seus residentes. A tendência deles é de serem menos otimistas sobre o potencial de ação coletiva como veículo de desenvolvimento comunitário, tendendo a considerar como reduzidos os benefícios ao apoio a tais causas.

\section{Dois tipos gerais de empreendedores}

Se classificarmos cada proprietário de empreendimento investigado de acordo com sua localização diante de cada par antitético identificado, dois tipos distintos emergem de forma praticamente automática. Um primeiro tipo, composto de proprietários localizados no centro histórico da cidade. São, principalmente, não nativos e que se encontram na parte mais refinada da categoria de empreendimentos "joia”. Veem seus negócios como centrais à sua identidade pessoal e ao seu estilo de vida, valorizam o desenvolvimento de relações com seus profissionais e buscam a prosperidade a longo prazo para a comunidade, assim como a preservação de seu "sabor local', por meio de ações mais coletivas.

A segunda categoria é composta por nativos arrendatários de propriedades no centro histórico e, em especial, por proprietários localizados na periferia. São proprietários de empreendimentos descritos como "bijuteria", nos quais se mantêm relações mais instrumentais com as equipes de trabalho. São mais orientados para o curto prazo e para os lucros imediatos. São, igualmente, mais individualistas em relação à comunidade e suas políticas. Há exceções a esse padrão, principalmente entre os não nativos que chegaram mais tardiamente à cidade e dispunham de poucos recursos para adquirirem propriedades no centro histórico da cidade, os quais, no entanto, tendem a se encaixar mais na primeira categoria proposta. Entretanto, como tipos ideais, essas duas categorias parecem-nos significativas para acentuar as principais diferenças sociais que dividem os empreendedores da comunidade.

\section{Empreendedores, tipologias de empreendedores e penturbia}

No início deste artigo nos propusemos a investigar a relação entre a emergência de uma penturbia brasileira e os atores sociais - especialmente os empreendedores - que operam nesse novo espaço socioeconômico. Em seguida, descrevemos a evolução da comunidade de Tiradentes e, apoiando-nos em entrevistas semiestruturadas com membros dessa comunidade, induzimos dois tipos de empreendedores locais, os quais emergiram diretamente dos pares antitéticos empregados pelos entrevistados. Tendo lançado esse fundamento, prosseguimos agora no confronto entre os nossos dados - categorias indutivas - e os atributos de penturbia identificados por Lessinger, bem como com conceitos e tipos encontrados na literatura sobre empreendedorismo. Esperamos, assim, oferecer senão uma compreensão mais ampla do empreendedorismo no contexto comunitário, em geral, pelo menos um entendimento mais abrangente em um importante destino turístico brasileiro. No mínimo, porém, trataremos de 
compreender o empreendedorismo em Tiradentes, seus diferentes tipos de empreendedores, suas identidades e interesses, assim como suas inter-relações no interior da dinâmica de uma comunidade de vanguarda no Brasil.

\section{Empreendedores e construção da penturbia}

Mesmo sem se apoiar na literatura internacional sobre empreendedorismo, não é difícil imaginar efeitos recursivos entre fatores comunitários e posturas empreendedoras a partir do caso em análise. Se desde o início a comunidade não dispusesse de um conjunto de prédios históricos situados numa localização mais ou menos intocada, é improvável que o empreendedor de caráter mais "Conservador" (Tipo 1) houvesse sido atraído à comunidade. O desenvolvimento subsequente, se ocorresse, provavelmente haveria simplesmente negligenciado ou "derrubado" a área histórica da cidade e Tiradentes nunca teria se tornado um destino turístico "refinado". Se a segunda categoria, que poderíamos chamar de empreendedor "Orientado para o Crescimento" estivesse ausente é, igualmente, improvável que o atual volume de tráfego de turistas houvesse sido atingido, tanto pelo fato de os empreendedores "Conservadores" terem pouco interesse no crescimento econômico, quanto porque seus modelos de negócios poderiam não ser apropriados a economias centradas na escala. Por outro lado, se a categoria orientada ao crescimento passasse a dominar Tiradentes, a cidade, provavelmente, perderia muito de seu atual apelo, pelo menos para o mercado de elite, e, possivelmente, com o passar do tempo, também para o mercado mais popular, devido à degradação de seus bens históricos e culturais. O que se percebe é que, pelo menos atualmente, a combinação dos dois tipos de empreendedores detectados permite que a cidade, como um todo, consiga ter "sucesso" em lidar com os dois segmentos de mercado (elite e popular), o que provavelmente eleva sua renda. Ademais, o sistema político atual, controlado por tradicionais famílias locais, parece pouco interessado em qualquer alteração nessa configuração, quer ao se beneficiar do aumento de arrecadação advinda da expansão dos empreendimentos "orientados pelo crescimento", quer não incorporando, de forma efetiva, uma agenda mais de longo prazo, conforme preconizada pelos "empreendedores conservadores". Se o atual sistema político fosse menos inerte, é possível que decisões, direcionadas a favorecer uma das orientações, pudessem levar ao domínio de uma delas sobre a outra. Desse modo, a ecologia da comunidade de Tiradentes parece permitir a coexistência dos dois tipos de empreendedores identificados, auferindo benefícios de ambos, até que chegue a hora em que uma das facções se torne dominante.

\section{Tiradentes e a penturbia de Lessinger}

Essa dinâmica oferece, imediatamente, um complemento importante ao pensamento original de Lessinger. Talvez por causa de sua formação e orientação econômica, esse autor veja as forças em ação que levam à criação da penturbia de forma mais macro e inexorável — mudan- 
ças na tecnologia e ecologia levarão a correspondentes mudanças nos valores culturais, nos preços imobiliários, assim como na organização e ocupação do espaço geográfico. De fato, o nível macro de análise que empregou e o uso de dados quantitativos no âmbito da população de comarcas americanas dificultariam uma visão diferente.

Entretanto, quando penetramos em uma comunidade onde esses fatores macroeconômicos estão em curso, constata-se que diferentes atores respondem às forças econômicas de maneiras distintas, as quais, em conjunto, determinam até que ponto a comunidade vai assumir a natureza de uma penturbia. Em outras palavras, as dimensões da cultura da penturbia, de comunhão do homem com a natureza, com a arte, com a memória histórica, com o comunitarismo, com o voluntarismo e com a conservação dos recursos naturais são socialmente construídas e ainda são o foco de toda espécie de conflitos, manobras, negociações, alianças e mobilizações, bem aos moldes de sociólogos construtivistas, como Bordieu (2003, 2008). Esse achado é de suma importância na medida em que sugere que o surgimento da penturbia é um processo não só econômico, mas, eminentemente, social, que exige empenho e coragem por parte dos atores e protagonistas nele envolvidos. Com esse ponto firmemente em mente passa a ser útil considerar a literatura internacional sobre empreendedorismo na análise do caso Tiradentes e vice-versa.

\section{O estudo de campo à luz das tipologias existentes sobre empreendedores}

As categorias que induzimos a partir de nossa análise da história de Tiradentes e das entrevistas com nossos respondentes nos permitem insights sobre importantes dinâmicas sociais e econômicas da cidade, mas os dois tipos gerais de empreendedores que derivamos ainda não estão lapidados. Dentro das duas categorias gerais de "Conservador" e "Orientada para o Crescimento" encontramos importantes nuances e variações que merecem atenção. Por exemplo, muitos dos estabelecimentos localizados na periferia não são orientados para o crescimento e empregam relações personalistas com seus profissionais (embora não "desenvolvimentistas"), em vez de impessoais. Mais que isso, nossas análises post hoc dos dados de campo permitiram paralelos e desvios férteis, quando comparadas às tipologias de empreendedores existentes na literatura, os quais merecem maior atenção, em trabalhos futuros. Embora o espaço não permita uma exploração aprofundada dessas relações, acreditamos que será útil fornecer uma indicação de alguns dos pontos de contato observados.

\section{Artesãos e oportunistas}

Apesar da importância dos dois tipos de empreendedores identificados em Tiradentes para a dinâmica social e econômica da cidade, até recentemente não se registrava grande interesse na literatura internacional em tipologias dessa natureza. Na verdade, até onde temos conhecimento, as primeiras tipologias de empreendedores contendo mais que três categorias foram 
propostas por volta de 2009 (Stinchfield, 2009; Zahra et al., 2009). Mesmo assim, acreditamos que a incipiente literatura internacional possa oferecer insumos teóricos úteis para o nosso estudo e vice-versa.

É interessante destacar que a tipologia mais antiga e mais influente que identificamos na literatura internacional - a dicotomia de Smith, de 1967 — parece ser bem relevante para Tiradentes. O estudo de campo sobre empreendedores norte-americanos feito por esse autor identificou dois tipos contrastantes que ele classificou de "artesão" (crafstman) e "oportunista" (opportunist). O artesão era, tipicamente, o filho (sua amostragem era toda masculina) de pais trabalhadores (colarinho azul), que haviam recebido treinamento técnico e talvez assistido a aulas em faculdades, mas que, normalmente, não haviam se formado em um curso superior. Tal "artesão" dedicava-se ao seu trabalho e fundava seu próprio negócio para evitar a interferência de gerentes e de sindicatos em sua vida profissional. Valorizava trabalhadores de alta qualidade e confiáveis, a quem conhecia e tratava bem, mas não estava particularmente interessado em crescimento ou em altos lucros.

O tipo contrastante de Smith, o "oportunista", advinha de uma família de classe mais alta e, normalmente, possuía um diploma superior em negócios ou em ciências humanas, mas não em um campo técnico ou de engenharia. Havia, normalmente, obtido experiência gerencial em outra firma antes de fundar a sua própria. Além disso, dava valor ao empreendimento como um fim em si mesmo e, frequentemente, havia sonhado, desde cedo, em ter seu próprio negócio. Ele acreditava na gestão da demanda por meio de marketing e promoção e valorizava o crescimento de seu empreendimento, mesmo que isso envolvesse o recurso a banqueiros e sócios (coisa que o artesão evitava). As décadas subsequentes trouxeram replicações e pequenas variações ao padrão de Smith, que a falta de espaço não nos permite aqui discutir (Cooper et al., 1997; Filley e Aldag, 1978; Woo et al. 1991).

Os paralelos entre os "artesãos" e os "oportunistas", de Smith, e as categorias "orientados à conservação" e "ao crescimento", em Tiradentes, são evidentes e fascinantes quanto às suas semelhanças e diferenças. Os empreendedores "conservadores" de Tiradentes estão interessados na qualidade, possuem pequenos empreendimentos e estão menos interessados em crescimento e resultados financeiros, o que os torna muito parecidos com os "artesãos" de Smith. Entretanto, eles são totalmente o oposto em termos de origem de classe, nível de educação formal e, presume-se, grau de cosmopolitismo, sendo pessoas altamente educadas, originárias de classe alta e migrantes advindos de grandes cidades. Tal contraste é particularmente interessante, dado que a atividade artesanal é, historicamente, em países latinos, uma atividade de baixo status (Hawkins, 1984).

Os paralelos entre o "oportunista", de Smith, e os empreendedores "orientados para o crescimento" são também dignos de nota, assim como o fato de que, em Tiradentes, eles sejam, em bom número, pessoas de origem local com menor nível de educação formal, status social e capital cultural. Tal inversão, inesperada, sem dúvida, traz implicações à nossa compreensão do empreendedorismo em seu contexto sociocultural. 


\section{Artistas e bricoleurs}

Uma tipologia de empreendedores mais recente nos ajuda, também, a interpretar algumas das diferenças que observamos dentro das duas amplas categorias identificadas em Tiradentes. Mais uma vez, o espaço não nos permite uma revisão extensa dessa literatura, mas três categorias derivadas de trabalhos recentes são ilustrativas e interessantes.

Independentemente de esforços para criar tipologias de empreendedores, no final do século XX, tanto os estudantes de empreendedorismo quanto o campo da gestão de negócios em geral começaram a observar desvios em relação ao planejamento linear clássico e à racionalidade em uma variedade de comportamentos. Dois desses comportamentos menos formalmente racionais, a arte e a bricolagem, eram aspectos do clássico Pensamento selvagem (1962) do antropólogo francês Lévi-Strauss, que estudantes de empreendedorismo, mais tarde, usaram para interpretar comportamentos que observaram entre empreendedores.

A bricolagem envolve a reconfiguração de recursos existentes que estão disponíveis "bem à mão" para gerar soluções inovadoras a problemas encontrados (Baker e Nelson, 2005; Garud e Karnoe, 2003; Harper, 1987; Kincheloe, 2001). Entre outras definições que poderiam ser propostas, a arte envolve a integração de variados elementos com a intenção de causar uma reação estética ou emocional no observador. Nem a bricolagem, nem a arte são formalmente racionalistas, embora ambas impliquem comportamentos reconhecíveis (Stinchfield, 2009; Stinchfield, Nelson e Wood, 2010). Descobrimos que os comportamentos que são associados tanto à arte quanto à bricolagem são significativos quando lidamos com o empreendedorismo em Tiradentes.

De acordo com Stinchfield (2009) e Stinchfield e colaboradores (no prelo), os artistas, como os artesãos, estão interessados em empreendedorismo mais como um veículo de expressão pessoal do que para o crescimento ou a acumulação de riqueza. Eles se diferenciam, entretanto, no fato de que sua identidade pessoal envolve uma necessidade de serem criativos e originais, a qual ultrapassa a definição de qualidade dos artesãos, determinada pela tradição e pelo contexto comunitário.

O artista é mais "genioso", individualista, e menos participante em uma comunidade limitada. Suas redes sociais são mais amplas, mas seus laços são mais fracos, com menos ligações pessoais e lealdade.

Os bricoleurs, por seu turno, também são diferentes. São oportunistas, mas diferentemente dos "oportunistas" de Smith, eles não estão interessados em agarrar as oportunidades em grande escala, nem necessariamente interessados no crescimento, nem em expandir seus negócios como parte de sua identidade pessoal. Em vez disso, estão bem conscientes das oportunidades locais que se apresentam mais concretamente sob a forma de elementos disponíveis, mais baratos ou gratuitos, que podem fornecer benefício econômico por meio de uma recombinação ou de um processamento mínimo, porém criativo (Baker e Nelson, 2005). Frequentemente, conduzem experiências para criar novas soluções para problemas, mas não para aperfeiçoá-las ou difundi-las. No mais, dependem de uma pequena rede local de colaboradores com quem possam trocar tarefas, materiais e informação (Zahra et al., 2009). 
Outra categoria sugerida pela literatura baseada em Lévi-Strauss é o engenheiro, o qual utiliza a abstração, pensamento linear, planejamento e operações formais da ciência para criar e administrar empreendimentos racionais e eficientes que maximizam lucro e crescimento (Baker e Nelson, 2005). O engenheiro corresponde, em seus métodos e visão de mundo, ao gestor científico de Taylor e aos ideais funcionalistas e objetivistas que os textos clássicos de administração, em todo o mundo, consideram normais (Wood e McKinley, 2010).

Os três tipos parecem possuir papéis definidos, se não críticos, em Tiradentes. Os artistas com tendência a se localizarem no centro histórico da cidade produzem e revendem produtos e serviços de alto nível, desejam e experimentam pouco crescimento, são não nativos, mais individualistas que os artesãos e menos emocionalmente ligados à cidade e ao seu futuro. São também menos ligados e interessados em suas tradições e identidade. São aliados naturais dos artesãos, na medida em que se beneficiam de seus esforços para conservar os bens culturais da cidade e, via de regra, não competem entre si. Existem poucos deles, mas essa minoria exerce impacto substancial na posição e no status da cidade devido à sua reputação, nacional e internacional, e a seus contatos. Para a cidade, eles são uma fonte de notoriedade. Para os artistas, Tiradentes é um excelente local para se produzir e vender arte.

Os bricoleurs estão, provavelmente, em maior número que qualquer outra categoria, mas são, certamente, menos envolvidos nas questões culturais da cidade. Eles são normalmente nativos, com pequenas propriedades nos arredores, as quais podem ser exploradas comercialmente. Se possuem uma casa em uma rua movimentada, são capazes de, rapidamente, adicionar uma pequena construção ("puxadinho") e vender itens de conveniência ou "lembrancinhas da cidade". Se suas residências não estiverem localizadas em uma rua movimentada, constroem quartos de hóspedes para alugar ou mesmo hospedam-se em casas de parentes para alugar sua propriedade para turistas durante a alta temporada ou feriados prolongados. Em outros termos, os bricoleurs não estão interessados na prosperidade a longo prazo da cidade e são menos motivados pela estética que os proprietários de empreendimentos "joia” e mesmo que "bijuteria", mas aumentavam a capacidade da cidade em absorver um maior tráfego de turistas a valores que permitem o acesso à cidade àqueles que, de outra forma, não poderiam pagar os valores pedidos por aqueles empreendimentos, ou que não caberiam, fisicamente, durante os períodos de alta demanda. Desprezados como incultos ou "filisteus" pela facção "conservadora", seu número e seus laços familiares na cidade, sem dúvida, ajudaram a evitar que os políticos locais promulgassem leis ou fizessem cumprir decretos que regulamentassem pequenos empreendimentos ou padrões estéticos e códigos de construção fora da área central da cidade.

Em Tiradentes, são poucos os empreendimentos que correspondem, rigorosamente, à tipologia de "engenheiros", mas esses poucos são grandes, prósperos e importantes. Boa parte deles foi fundada por nativos e passou por uma fase de bricolagem até um ponto em que a disciplina e ambição do fundador levaram à profissionalização do negócio. Sem as limitações e escrúpulos provindos da visão romântica de Tiradentes detida pelos artesões de fora, nem os gostos e identidade rebuscados dos artistas, os "engenheiros" reconheceram as oportunidades advindas da redescoberta artística da cidade e experimentaram ideias e produtos novos utili- 
zando técnicas baratas e informais da bricolagem. Diferente dos demais, quando o engenheiro constatava, por métodos informais, que um produto ou serviço tinha potencial, ele adquiria os recursos e métodos formais, racionais que permitam sua rápida produção e expansão. Os engenheiros de Tiradentes foram os que adotaram as técnicas e métodos da gestão norteamericana (management) com afã. O resultado dessa postura foi o estabelecimento e rápido crescimento de grandes negócios que trouxeram fluxos significativos de capital à comunidade e patrocinaram grandes eventos e festivais que chegam a triplicar a população da cidade nos dias de sua realização.

\section{Reflexões finais}

Pode-se fazer uma caricatura, senão caracterizar o pensamento tradicional sobre a criação de empresas como algo que segue um de dois extremos analíticos. Por um lado, existe uma visão que considera os empreendedores como indivíduos quase míticos e totalmente diferentes das outras pessoas. Tal visão os considera como pessoas cuja energia e gênio os leva a agarrar oportunidades e criar novas riquezas onde os outros não conseguem (Collins e Moore, 1964; Carland et al., 1996; Hull et al., 1980; Miller, 1983; Miner, 2000). O pensamento econômico clássico (Shumpter, 1934, 1942) e o pensamento neoconservador, principalmente o do tipo de AynRand, estão mais perto de tal extremo (Brockhaus, 1980). Por outro lado, encontramos a ideia de que as forças de nível macro - tecnológicas e econômicas — criam oportunidades para novos empreendimentos que são descobertos aleatoriamente por pessoas que, sem dispor de nenhuma virtude própria, se encontram no lugar certo na hora certa. O exemplo mais influente desse segundo extremo pode ser encontrado na visão da ecologia populacional das organizações, que considera a criação de empreendimentos em termos da exploração de "nichos" de recursos ambientais, recursos estes explorados por atores que possuam as características que correspondem às necessidades de certo "nicho" (Hanan e Freeman, 1984). Com o tempo, essas posições extremas vêm sendo moderadas por novos estudos e perspectivas, mas a tendência de atribuir o surgimento de empresas ou a grandes talentos individuais, ou a forças econômicas impessoais e incontroláveis, ainda é forte.

A dinâmica causal que apercebemos por meio de nossa etnografia de Tiradentes é bastante diferente desses dois extremos. Sem dúvida, os acidentes da história e geografia forjaram, em Tiradentes, uma configuração de recursos físicos de certa forma única. O que aconteceu depois do abandono da cidade, entretanto, foi muito mais dependente de valores e reações idiossincráticas individuais e coletivas. Primeiramente, um grupo de artistas proeminentes considerou o acervo arquitetônico abandonado esteticamente simbólico e digno de conservação. Depois, uma matriarca influente mobilizou recursos pessoais e políticos para preservar e facilitar o acesso à "descoberta" dos artistas modernistas. Em um ponto subsequente, pessoas abastadas mudaram-se para Tiradentes, atraídas por um estilo de vida artesanal no meio rural, criando uma infraestrutura de pousadas de elite. Daí, outro conjunto de artistas começa a produzir filmes e novelas de época. A infraestrutura fornecida pela leva inicial de "artesões" e 
a notoriedade criada pelos produtores de mídia atraíram mais visitantes, incluindo pessoas de poder aquisitivo mais modesto. Mais uma onda de "artesões" fugindo e buscando refúgios do ambiente corporativo cria novos atrativos hoteleiros e gastronômicos. Influenciados por esse boom de desenvolvimento, nativos "oportunistas" utilizam-se de bricolagem para aumentar a capacidade de abrigar mais turistas e, finalmente, engenheiros exploram a escala econômica propiciada pelo aumento no fluxo turístico, criando empreendimentos de grande escala.

Como as origens, identidades pessoais e estilos empresariais desses atores são tão diversos, nenhum meio formal ou informal de coordenação e mobilização une os empreendedores de Tiradentes, muito menos foi possível identificar um líder carismático ou dotado de outro atributo capaz de impacto dominante na comunidade. Muito pelo contrário, o tecido socioeconômico criado pelos diversos tipos de empreendedores em Tiradentes produziu um "sucesso econômico inovativo" que pode a qualquer momento perder seu apelo como perturbia brasileira de vanguarda. Basta os "bricoleurs" ou "engenheiros" conquistarem ascendência plena que a comunidade mudará de caráter e o ambiente que os ecologistas veem como um dado inexorável se alterará. Sugerimos, portanto, que, pelo menos no que se trata do desenvolvimento econômico das comunidades pequenas, não basta procurar explicações somente nas grandes personagens ou nas grandes forças econômicas, mas também nos variados anseios, identidades e modelos administrativos das pessoas que se atrevem a apostar suas fortunas na comunidade e nas interações, assim como nas tensões que as interligam.

\section{Referências}

AUSBEL, K. Restoring the Earth: visionary solutions from the Bioneers. Tiburon, Ca: H.J. Kramer, 1997.

BAKER, T.; NELSON, R. Creating something from nothing: resource construction through entrepreneurial bricolage. Administrative Science Quarterly, v. 50, p. 329-366, 2005.

BOURDIEU, P. A distinção: crítica social do julgamento. São Paulo: Edusp, 2008.

BOURDIEU, P. A economia das trocas simbólicas. São Paulo: Perspectiva, 2003.

BOWEN, G. Grounded theory and sensitizing concepts. International Journal of Qualitative Methods, v. 5, n. 3, p. 1-9, 2006.

BROCKHAUS, R. Risk taking propensity of entrepreneurs. Academy of Management Journal, v. 23, n. 3, p. 509-520, 1980.

CARLAND, J.; CARLAND, J.D.; STEWART, W. Seeing what's not there: the enigma of entrepreneurship. Journal of Small Business Strategy, v. 7, n. 1, p. 1-20, 1996.

COLLINS, O.; MOORE, D. The enterprising man. East Lansing, MI: Michigan State University Press, 1964. 
COOPER, A.; RAMACHANDRAN, M.; SCHOORMAN, D. Time allocation patterns of craftsmen and administrative entrepreneurs: implications for financial performance. Entrepreneurship: Theory \& Practice, v. 22, n. 2, p. 123-136, 1997.

DANA, L.P. Entrepreneurship in Bolivia: an ethnographic study. International Journal of Business and Emerging Markets, v. 3, n. 1, p. 75-87, 2011.

DAVIDSON, P. Culture, structure and regional levels of entrepreneurship. Entrepreneurship Theory and Practice, v. 7, p. 41-62, 1995.

DE SOTO, H. The mystery of capitalism. New York: Basic Books, 2000.

DENZIN, N.; LINCOLN, Y. Handbook of qualitative research. $2^{\text {nd }}$ ed. Thousand Oaks, CA: Sage Publications, 2000.

DEY, I. Grounding categories: In: BRYANT, Z.; CHARMAZ, T.A. (Ed.). The Sage handbook of grounded theory. Los Angeles: Sage, 2007.

FAORO, R. Os donos do poder: formação do patronato político brasileiro. Porto Alegre: Globo, 1979.

FILLEY, A.; ALDAG, D. Characteristics and measurement of an organizational typology. Academy of Management Journal, v. 21, n. 4, p. 578-591, 1978.

FLICK, U. Introdução à pesquisa qualitativa. Porto Alegre: Artmed, 2009.

FREEMAN, J.H.; AUDIA, P.G. Community ecology and the sociology of organizations. Annual Review of Sociology, v. 32, p. 145-169, 2006.

FROTA, L.C. Tiradentes: retrato de uma cidade. Rio de Janeiro: Bem-Te-Vi, 2005.

GARUD, R.; KARNOE, P. Bricolage versus breakthrough: distributed and embedded agency in technology entrepreneurship. Research Policy, v. 32, n. 2, p. 277-300, 2003.

GLASER, B. Sensitivity: advances in the methodology of grounded theory. Mill Valley, CA: Sociology Press, 1978.

GLASER, B. Basics of grounded theory analysis: emergence vs. forcing. Mill Valley, CA: Sociology Press, 1992.

GLASER, B.; STRAUSS, A. The discovery of grounded theory: strategies for qualitative research. New York: Aldine de Gruyter, 1967.

GIOIA, D.A.; THOMAS, J.B. Identity, Image and issue interpretation: sensemaking during strategic change in academia. Administrative Science Quarterly, v. 41, p. 370-403, 1996.

HANNAN, M.; FREEMAN, J. Structural inertia and organizational change. American Sociological Review, v. 49, n. 2, p. 149-164, 1984.

HARPER, D. Working knowledge: skill and community in a small shop. Chicago/London: University of Chicago Press, 1987.

HAYNIE, J.M.; SHEPHERD, D.A. A measure of adaptive cognition for entrepreneurship research. Entrepreneurship, Theory and Practice, v. 33, n. 3, p. 695-714, 2009. 
HAWKINS, J. Inverse images: the meaning of culture, ethnicity and family in post colonial Guatemala. Las Cruzes, NM: New Mexico University Press, 1984.

HICKS, S. Explaining postmodernism. San Jose, CA: Scholarly Pucliations, 2004.

HINDLE, K. How community context affects entrepreneurial processes. Entrepreneurship and Regional Development, v. 22, p. 599-647, 2010.

HULL, D.; BOSLEY, J.; UDELL, G. Renewing the hunt for the heffalump: identifying potential entrepreneurs by personality characteristics. Journal of Small Business Management, v. 18, n. 1, p. 11-18, 1980.

KINCHELOE, J. Describing the bricolage: conceptualizing a new rigor in qualitative research. Qualitative Inquiry, v. 7, n. 6, p. 679-692, 2001.

LEE, C.M.; MILLER, W.; HANCOCK, M.; ROWAN, H. (Ed.). The Silicon Valley edge: a habitat for innovation and entrepreneurship. Stanford, CA: Stanford University Press, 2000.

LESSINGER, J. Regions of opportunity. New York: Random House, 1986.

LESSINGER, J. The emerging region of opportunity. American Demographics, v. 9, p. 33-37, 1987.

LESSINGER, J. Penturbia: where real estate will boom after the crash of suburbia. Seattle, WA: Socioeconomics, 1991.

LESSINGER, J. Schizomaina: split society, perilous economy. Seattle, WA: Socioeconomics, 2003.

LESSINGER, J. An economics of the long run. Seattle, WA: Socioeconomics, 2008.

LÉVI-STRAUSS, C. The savage mind. Chicago: The University of Chicago Press, 1966.

LINCOLN, Y.; GUBA, E. Naturalistic inquiry. Newbury Park: Sage, 1985.

MALLMANN, T.D.M.; BORBA, B.W.; RUPPENTHAL, J.E. Avaliação da tipologia dos empreendedores residentes da incubadora tecnológica de Santa Maria utilizando o teste "Kersey Temperament Sorter”. In: ENCONTRO NACIONAL DE ENGENHARIA DE PRODUÇÃO, XXV, Porto Alegre, 2005. Anais do XXV Enegep. Porto Alegre, 2005.

MCMULLEN, J.; SHEPHERD, D.A. A theory of entrepreneurial action. In: KATZ, J.; SHEPHERD, D.A. (Es.). Advances in entrepreneurship, firm emergence and growth. Greenwich, CT: JAI Press, 2003.

MEPPEN, T. The discursive community: evolving institutional structures for planning sustainability. Ecological Economics, v. 34, p. 47-61, 2000.

MEZIAS, S.J.; KUPERMAN, J. Economic action and social structure: the problem of embeddedness. American Journal of Sociology, v. 91, n. 3, p. 481-510, 2001.

MILES, M.; HUBERMAN, A. Qualitative data analysis: an expanded sourcebook. $2^{\text {nd }}$ ed. Thousand Oaks, CA: Sage, 1994.

MILLER, D. The correlates of entrepreneurship in three types of firms. Management Science, v. 29, n. 7, p. 770-791, 1983. 
MINER, A.; BASSOFF, P.; MOORMAN, C. Organizational improvisation and learning: a field study. Administrative Science Quarterly, v. 46, p. 304-337, 2001.

MINER, J.B. Testing a psychological typology of entrepreneurship using business founders. Journal of Applied Behavioral Science, v. 36, n. 1, p. 43-69, 2000.

OWEN-SMITH, J.; POWELL, W.W. Knowledge networks as channels and conduits: the effects of spillovers in the Boston biotech community. Organization Science, v. 15, p. 5-21, 2004.

PADGETT, D.K. Coming of age: theoretical thinking, social responsibility, and a global perspective on qualitative research. In: PADGETT, D.K. (Ed.). The qualitative research experience. Belmont, CA: Wadsworth/Thompson Learning, 2004.

REICH, R.B. The work of nations. New York: Knopf, 1991.

RIFFKIN, J. The end of work. New York: Putnam, 1995.

SANT'ANNA, A.S.; NELSON, R.E.; CAMPOS, M.S. Liderança e reconversão de funções econômicas de cidades: o caso Tiradentes. Nova Lima: FDC/Fapemig, 2011. (Relatório de Pesquisa)

SANT'ANNA, A.S.; NELSON, R.E.; OLIVEIRA, F.B. Empreendedorismo e desenvolvimento do turismo em Tiradentes. Revista Acadêmica Observatório de Inovação do Turismo, v. 6, n. 3, 2011.

SARASVATHY, S. The questions we ask and the questions we care about: reformulating some problems in entrepreneurship research. Journal of Business Venturing, v. 19, p. 707-717, 2004.

SHUMPETER, J. A. The theory of economic development. Cambridge, MA: Harvard University Press, 1934.

SCHUMPETER, J. Capitalism, socialism and democracy. New York: Harper, 1942.

SMITH, A. The entrepreneur and his firm: the relationship between type of man and type of company. East Lansing, MI: Michigan State University, 1967.

STINCHFIELD, B. Toward a theory of entrepreneurial work. Doctoral (dissertation) - Southern Illinois University, 2009.

STINCHFIELD, B.; NELSON, R.E.; WOOD, M. Entrepreneurial opportunities: bricolage, art, craft, engineering and brokerage. Lauzanne, Switzerland: Babson College Entrepreneurship Research Conference, 2010.

STINCHFIELD, B.; NELSON, R.E.; WOOD, M. Learning from Lévi-Strauss legacy: bricolage, art, craft, engineering and brokerage. In: Entrepreneurship theory and practice. (no prelo).

TOFFLER, A. The third wave. London: Pan, 1980.

WOO, C.; COOPER, A.; DUNKELBERG, W. The development and interpretation of entrepreneurial typologies. Journal of Business Venturing, v. 6, p. 93-114, 1991.

WOOD, M.S.; McKINLEY, W. The production of entrepreneurial opportunity: a constructivist perspective. Strategic Entrepreneurship Journal, v. 4, n. 1, p. 66-84, 2010. 
ZAHRA, S.; GEDAJLOVIC, E.; DONALD, O.; NEUBAUM, D.; SHULMAN, J. A typology of social entrepreneurs: motives, search processes and ethical challenges. Journal of Business Venturing, v. 24, n. 5, p. 519-532, 2009.

Reed Elliot Nelson é professor do PMDA da Universidade Nove de Julho (Uninove). E-mail: renelson@ siu.edu.

Anderson de Souza Sant'Anna é professor da Fundação Dom Cabral e do Programa de Pós-Graduação em Administração da Pontifícia Universidade Católica de Minas Gerais (PUC-MG). E-mail: anderson@ fdc.org.br. 
